\title{
Ultrastructural changes of Haematococcus pluvialis (Chlorophyta) in process of astaxanthin accumulation and cell damage under condition of high light with acetate
}

\author{
Bangxiang He, Lulu Hou, Feng Zhang, Xiaomei Cong, Zhendong Wang, Yalin Guo, Jiawei \\ Shi, Ming Jiang, Xuecheng Zhang and Xiaonan Zang*
}

Key Laboratory of Marine Genetics and Breeding, Ministry of Education, Ocean University of China (OUC), Qingdao 266003, Shandong, China

\begin{abstract}
Haematococcus pluvialis is a commercial microalga that can produce high quantities of astaxanthin. Under induced conditions, some important changes in the subcellular structures related to astaxanthin accumulation were observable. For example, a large number of astaxanthin granules, oil structures and starch granules appeared in the thick-walled cells; Astaxanthin granules gradually dissolved into the oil structures and spread throughout the entire cell with the fusion and diffusion process of oil structures during the middle and late stages of induction; The plastoglobules were closed to the newly formed structures, and some plastoglobules would abnormally increase in size under stress. Based on observations of cell damage, the degradation of membrane structures, such as chloroplasts, was found to be the primary form of damage during the early stage of induction. During the middle stage of induction, some transparent holes were exposed in the dissolving astaxanthin granules in the cytoplasm. In thick-walled cells, these transparent holes were covered by oil substances dissolving astaxanthin, thereby avoiding further damage to cells. Given the relatively few oil structures, in non-thick-walled cells, the transparent holes expanded to form multiple transparent areas, eventually resulting in the rupture and death of cells. These results suggested that the high level of synthesis and the wide range diffusion of oil explained the expansion of astaxanthin in H. pluvialis.
\end{abstract}

Key Words: astaxanthin; Haematococcus pluvialis; high light; plastoglobule; ultrastructure

Abbreviations: PGs, plastoglobules; TAG, triacylglycerol; TEM, transmission electron microscope imaging technique; ROS, reactive oxygen species

\section{INTRODUCTION}

Haematococcus pluvialis Flotow is the most commonly used microalga for the commercial production of natural astaxanthin, a red carotenoid and powerful biological antioxidant that has a bright red coloration, and is widely used for its antioxidant properties, and as a natural coloring agent in aquaculture (Lorenz and Cysewski
2000, Han et al. 2012, Ambati et al. 2014). Three main stages in the cellular cycle of $H$. pluvialis can be differentiated: flagellated vegetative green cells or zoospores, non-motile green cells (palmella) and mature red cyst cells or aplanospores (Fátima Santos and Mesquita 1984, Boussiba 2000, Naguib 2000, Fábregas et al. 2003). As $H$.
(9) \$ This is an Open Access article distributed under the terms of the Creative Commons Attribution Non-Commercial License (http://creativecommons.org/licenses/by-nc/3.0/) which permits unrestricted non-commercial use, distribution, and reproduction in any medium, provided the original work is properly cited.
Received February 23, 2020, Accepted May 22, 2020

* Corresponding Author

E-mail: xnzang@ouc.edu.cn

Tel: +86-185-6162-1817, Fax: +86-0532-8203-2789 
pluvialis changes from zoospores to cysts, the two equallength flagella disappear with the increase of cell volume and cell wall thickness (Boussiba 2000, Damiani et al. 2006, Evens et al. 2008). The large accumulation of astaxanthin, primarily in the form of ester (mono- or di-ester) (Kobayashi and Sakamoto 1999, Boussiba 2000, Gwak et al. 2014), is concentrated in the red cyst cells stages. Several factors, such as high-light intensities, high salinity, and oxidative stress, can promote the accumulation of astaxanthin (Kobayashi et al. 1993, Imamoglu et al. 2009, Focsan et al. 2017).

In H. pluvialis, the pathway of astaxanthin biosynthesis is now well established and include, the conversion of isopentenylpyrophosphate to $\beta$-carotene and then to astaxanthin (Grünewald et al. 2001, Chen et al. 2015, Ota et al. 2018). Chen proposed a model of astaxanthin biosynthesis in Haematococcus: $\beta$-carotene is exported from the chloroplast to the endoplasmic reticulum, where it is converted into astaxanthin. Next, astaxanthin esters finally form astaxanthin ester-containing lipid droplets (Chen et al. 2015). Wayama et al. (2013) provided vivid images of changes in the volume of astaxanthin and oil substances during the astaxanthin accumulation process of $H$. pluvialis through three-dimensional transmission electron microscope imaging technique. In H. pluvialis, approximately $95 \%$ of astaxanthin molecules are esterified with fatty acids and stored in triacylglycerol (TAG)rich cytosolic lipid bodies (oil globules) (Yuan and Chen 2000, Holtin et al. 2009, Chen et al. 2015). In vivo and in vitro experiments have indicated that astaxanthin esterification drive the formation and accumulation of astaxanthin (Chen et al. 2015). Hence, observations of changes in the structure of astaxanthin and oil globules under stress are important for further exploring the role of lipids in astaxanthin production.

The ability to accumulate astaxanthin in H. pluvialis represents an adaptation to habitats that exhibit strong radiation (Wang et al. 2010). In addition, astaxanthin plays an important role in the protection of the cell membrane and the alleviation of oxidative stress caused by reactive oxygen species (ROS) (Kobayashi et al. 1997, Naguib 2000, Wang et al. 2010). Han et al. (2012) pointed out that motile cells were more susceptible than non-motile cells to the oxidative stress caused by ROS under high light conditions, resulting in a decrease in population density and photobleaching. The ability of non-motile cells to survive under stress stem from the production of storage starch, neutral lipids, and astaxanthin. Therefore, observations of the cell wall (thicker in non-motile cells), the processes of cell damage, the accumulation astaxan- thin and other substances, and the classification of cells under induced conditions would facilitate the exploration of the protective effects of astaxanthin in H. pluvialis.

Plastoglobules are small particles $(30 \mathrm{~nm}-5 \mu \mathrm{m}$ in diameter) that show a high affinity for osmium tetroxide and attach to the thylakoid membranes of higher plants and green algae (Austin et al. 2006, Rottet et al. 2015, Lohscheider and Río Bártulos 2016). Plastoglobules are enriched in free fatty acids, TAGs, carotenoids and prenyl lipids and can vary in size and number in response to stress (Lohscheider and Río Bártulos 2016). In addition to the well-known function of carotenoid storage and sequestration (Steinmüller and Tevini 1985, Deruère et al. 1994, Vishnevetsky et al. 1999, Bréhélin et al. 2007), plastoglobules also have a specific enzymatic function in carotenoid biosynthesis (Ytterberg et al. 2006, Bréhélin et al. 2007). Because of the important role of plastoglobules in carotenoid metabolism, determining whether plastoglobule-like structures exist and how they change under induced conditions in $\mathrm{H}$. pluvialis is necessary for enhancing our understanding of astaxanthin accumulation.

\section{MATERIALS AND METHODS}

\section{Cell culture and treatments}

H. pluvialis (HOUC9) was stored in the Laboratory of Phycology at the Ocean University of China. Before the experiment, algae were activated twice. Next, 250-mL conical flasks were used to culture $100 \mathrm{~mL}$ of algal cells in modified Bold's Basal Medium (Tripathi et al. 1999), with a $12 \mathrm{~h}: 12 \mathrm{~h}$ light / dark cycle at $21 \pm 1^{\circ} \mathrm{C}$; the initial $\mathrm{pH}$ was adjusted to about 7 . The light intensity used for the growth of the green cells was $20-30 \mu \mathrm{mol} \mathrm{m}^{-2} \mathrm{~s}^{-1}$. When the cell concentration reached $4-5 \times 10^{5}$ cells $\mathrm{mL}^{-1}$, induction began. The induction was performed in sterilized $250-\mathrm{mL}$ conical flasks with $50 \mathrm{~mL}$ of the inducing medium added to $50 \mathrm{~mL}$ of algal culture at $23 \pm 1^{\circ} \mathrm{C}$; and the $\mathrm{pH}$ was adjusted to about 8-8.5. The induction medium contained $\mathrm{CH}_{3} \mathrm{COONa}\left(2 \mathrm{~g} \mathrm{~L}^{-1}\right), \mathrm{FeSO}_{4} \cdot 7 \mathrm{H}_{2} \mathrm{O}\left(20 \mu \mathrm{mol} \mathrm{L}^{-1}\right)$ and VB12 $\left(0.05 \mathrm{mg} \mathrm{L}^{-1}\right)$. The light intensity used for induction was $195 \mu \mathrm{mol} \mathrm{m}^{-2} \mathrm{~s}^{-1}$ and the light cycle was $12 \mathrm{~h}: 12 \mathrm{~h}$ light / dark. Green cells on the 10th day in the growth stage and induced cells on the 2nd, 4th, 6th, 8th, 10th, and 18th days in the induced stage were collected for ultrathin section observations. 

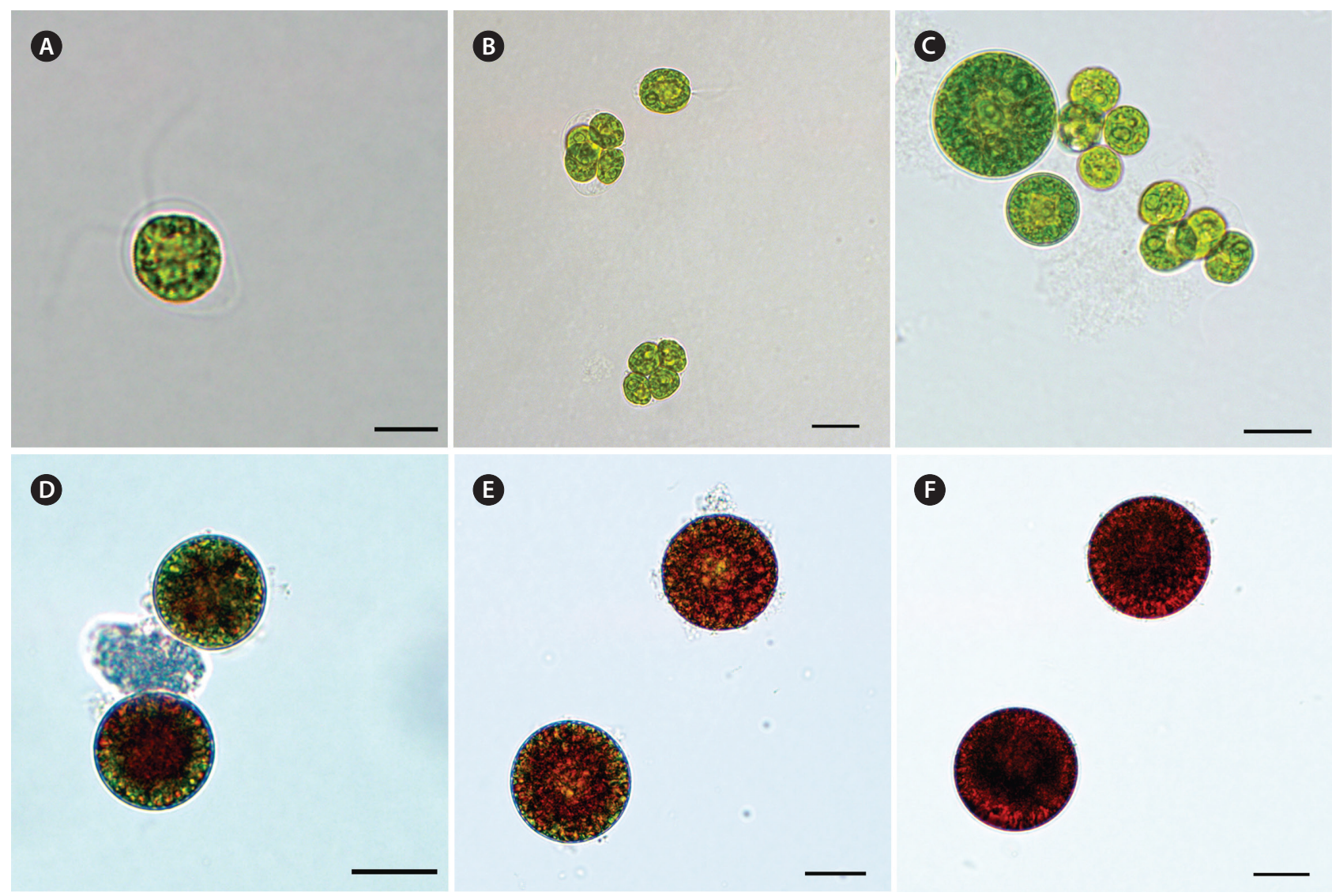

Fig. 1. Observation under an optical microscope of the two stages in Haematococcus pluvialis. (A) Motile cell with flagella. (B) Tetrasporophyte in rapid division period. (C) Non-motile cells in the late stage of green growth. (D) The cells in early stage under induced conditions. (E) The cells in mid stage under induced conditions. (F) The cells in later stage under induced conditions. Scale bars represent: A, $10 \mu \mathrm{m} ; \mathrm{B}-\mathrm{F}, 20 \mu \mathrm{m}$.

\section{Ultrathin section and observation}

During each timepoint, $10 \mathrm{~mL}$ of algal liquid was centrifuged for $2 \mathrm{~min}(2,000 \mathrm{rpm})$ to obtain the cell pellet. Next, the cells were pre-fixed using $3 \%$ glutaraldehyde in 0.2 $\mathrm{M}$ phosphate buffer solution ( $\mathrm{pH}$ 7-7.4) and then stored at $4^{\circ} \mathrm{C}$. When all of the samples were collected, $1 \%$ osmium tetroxide was used for post-fixation. After dehydrating with ethanol, embedding with Epon812, and trimming, the ultrathin section was obtained through the ultramicrotome for transmission electron microscope imaging technique (TEM) observation using H-7000 (Hitachi, Tokyo, Japan). All of the cells in every ultrathin section were observed. The diameters of the subcellular structures were estimated using the magnification and scale bar, and each measurement was made three times. Furthermore, the observation with the optical microscope were conducted using an Olympus BX41 (Olympus, Tokyo, Japan).

\section{RESULTS}

\section{Cell morphology in optical microscope}

With the optical microscope, we could observe the flagellum of the green motile cell during the green growth stage (Fig. 1A), the tetrasporophyte during the fast division period (Fig. 1B), and the green immovable cells (Fig. $1 \mathrm{C}$ ) as a result of the nutrient deficiency and increase in $\mathrm{pH}$ among other reasons during later vegetative growth stage. During astaxanthin accumulation, the algal cells tended to be round and the color gradually deepened, eventually resulting in deep red cyst cells (Fig. 1D-F).

\section{Ultrastructure characteristics of the green cell}

Ultrastructural images of the green cell (Fig. 2) revealed a transparent extracellular matrix surrounding the cell, with a thickness of approximately $0.7 \mu \mathrm{m}$ (Fig. 

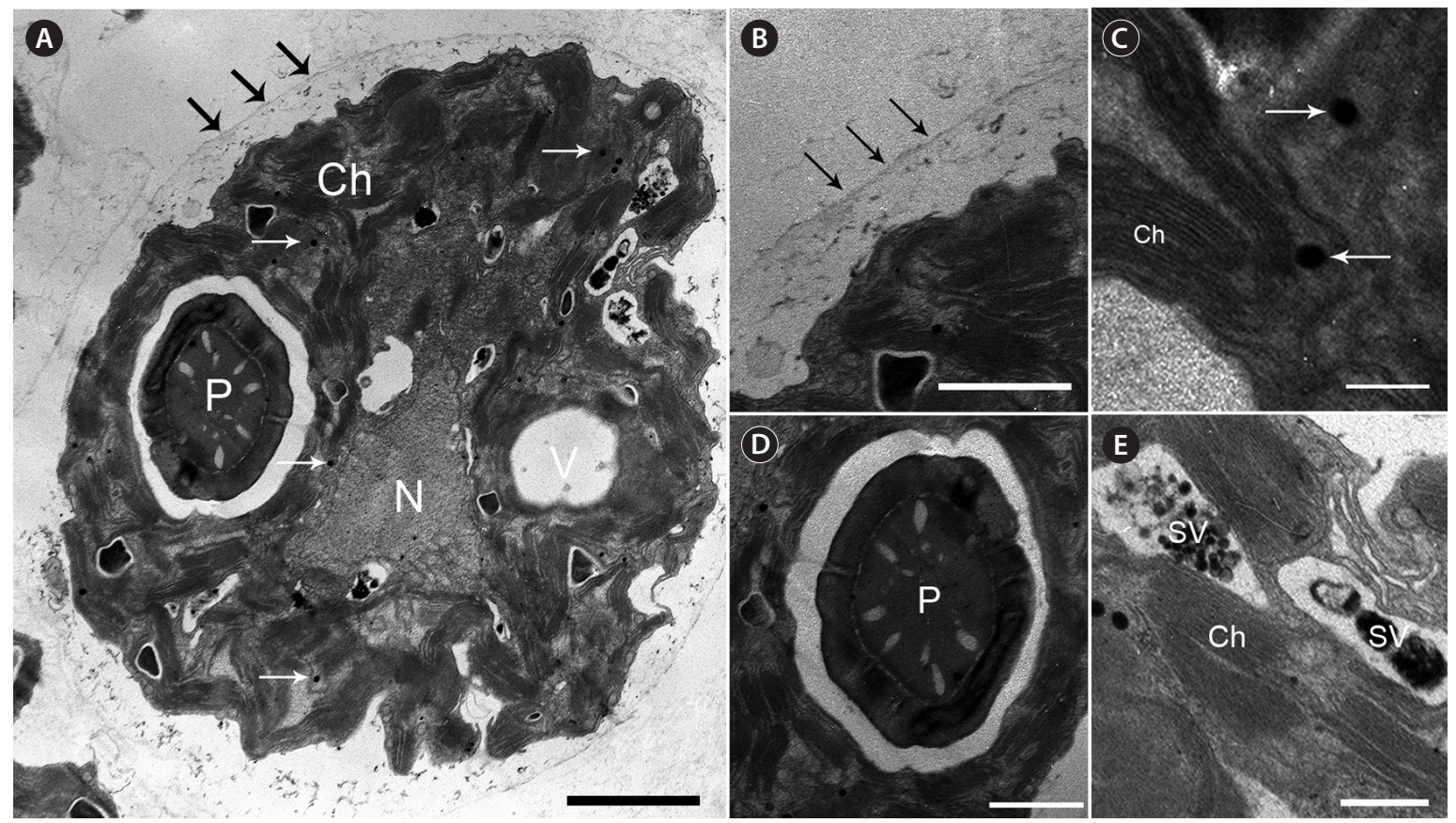

Fig. 2. Ultrastructure of a green cell. (A) Complete picture of green cell. (B) Extracellular matrix. (C) Chloroplast and plastoglobules. (D) Pyrenoid. (E) Small vacuole contain pigment. Ch, chloroplast; N, nucleus; P, pyrenoid; SV, small vacuole; V, vacuole. Black arrows, membrane of extracellular matrix; white arrows, plastoglobules. Scale bars represent: $A, 2 \mu \mathrm{m} ; \mathrm{B}, \mathrm{D} \& \mathrm{E}, 1 \mu \mathrm{m} ; \mathrm{C}, 0.2 \mu \mathrm{m}$.
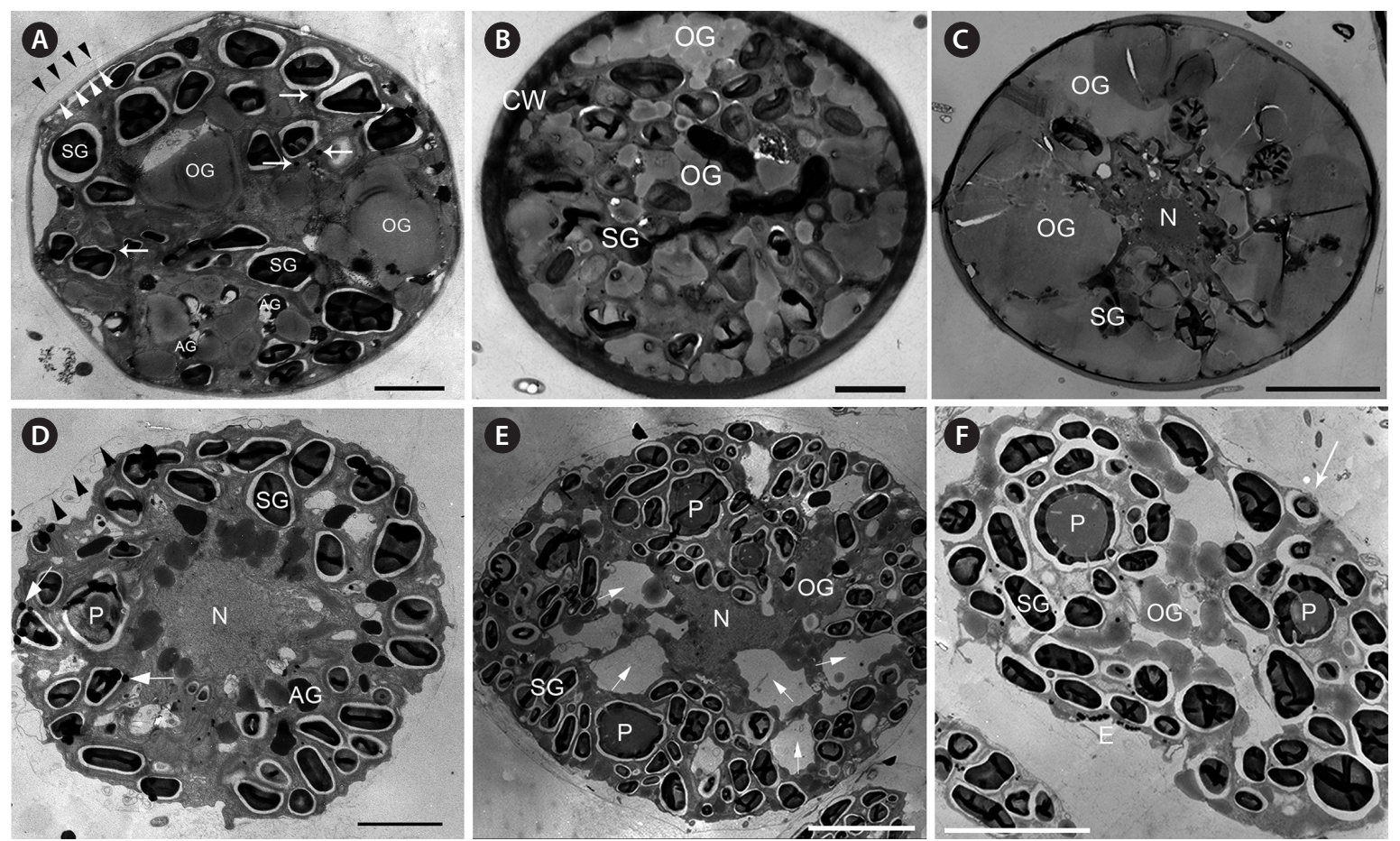

Fig. 3. Three types of cells under induced conditions. (A-C) Thick-walled cells on the fourth, tenth and eighteenth day under induced conditions, respectively. (D) Non-thick-walled cell on the eighth day. (E) The damaged cell. (F) A damaged cell on the verge of rupture. AG, astaxanthin granules; CW, cell wall; E, eyespot; N, nucleus; OG, oil granules; P, pyrenoid; SG, starch granules. Black and white arrowheads, membrane of extracellular matrix; white arrows, plastoglobules $(A \& D)$, transparent damage zone $(E)$, possible breaking point $(F)$. Scale bars represent: $A, B$ \& $D, 2$ $\mu \mathrm{m} ; \mathrm{C}, \mathrm{E} \& \mathrm{~F}, 5 \mu \mathrm{m}$. 

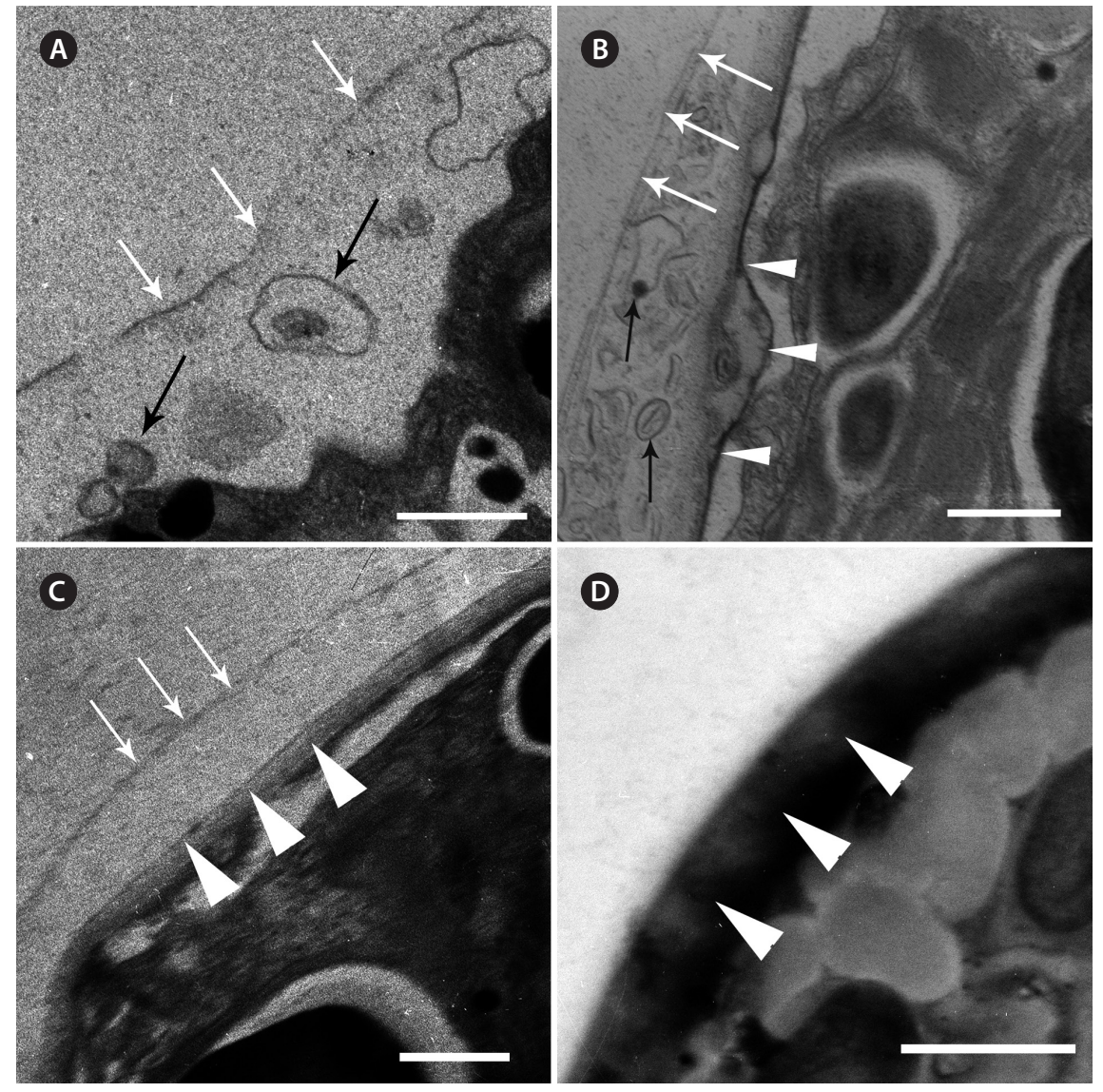

Fig. 4. Formation process of thick cell wall. (A) Substances appeared in extracellular matrix in non-thick-walled cell. (B) Substances appeared in extracellular matrix in thick-walled cell and appearance of initial secondary cell wall. (C) Secondary cell wall became thicker. (D) Complete formation of secondary thick wall and disappearance of extracellular matrix on 10th day. White arrows, membrane of extracellular matrix; black arrows, substances in extracellular matrix; white arrowheads, secondary cell wall. Scale bars represent: A-C, $0.5 \mu \mathrm{m} ; \mathrm{D}, 1 \mu \mathrm{m}$.

2B). In addition to a larger vacuole, the cell also had several small vacuoles inside (Fig. 2E). There were many developed chloroplasts (Fig. 2C), which had 10-20 layers of grana lamellae surrounding the periphery of the cell. An obvious pyrenoid was present in the chloroplasts, which had irregular elliptical shapes with diameters of 2.3-3.1 $\mu \mathrm{m}$ (Fig. 2D). In addition, there were several small osmiophilic globules (diameters around 40-60 $\mathrm{nm}$ ) with high densities of electron in the chloroplasts (Fig. 2C) (hereafter referred to as "plastoglobules").

\section{Ultrastructure characteristics of cells under induced condition}

All of the cells under induced conditions could be classified into three cell types: thick-walled cells, non-thickwalled cells, and severely damaged cells. Thick-walled cells (Fig. 3A-C) represented the most common cell mor- phology under induced conditions. The main characteristics of this cell type were the disappearance of extracellular matrix with the gradual formation of the secondary thick wall and the compaction of intracellular structures with a large number of astaxanthin granules, starch granules, and oil structures. Over time, cells were gradually filled with mixtures of oil and astaxanthin, which showed medium electron densities (Fig. 3A-C). Non-thick wall cells (Fig. 3D) were fewer and could only be observed in the early or middle stages under induced conditions. The main characteristics of non-thick-walled cells were the presence of the extracellular matrix with many astaxanthin and starch granules but fewer oil structures in the cytoplasm. Most of the severely damaged cells were characterized by non-thick-wall cells with many parts of the cell degrade and the formation of many transparent areas, some of which were even on the verge of rupture (Fig. 3E \& F). 

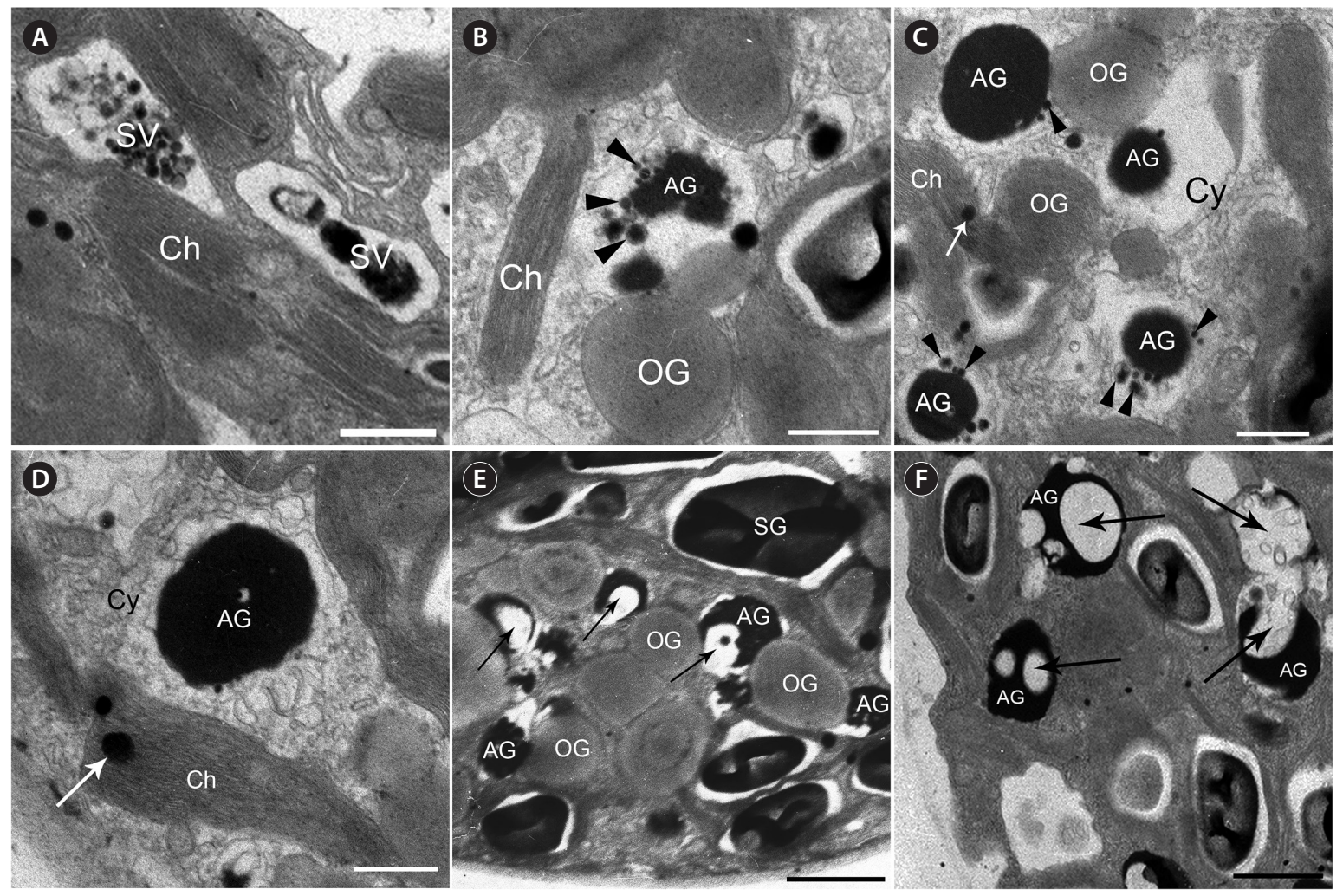

Fig. 5. Formation and change process of astaxanthin granules. (A) Small vacuole contained pigment granules. (B) Some small astaxanthin granules clustered together. (C) Bigger astaxanthin granules with small astaxanthin granules. (D) A big astaxanthin granule in cytoplasm and big plastoglobules in chloroplast. (E) Dissolution of astaxanthin granules in thick-walled cell. (F) Dissolution of astaxanthin granules in non-thick-walled cell. AG, astaxanthin granules; Ch, chloroplast; Cy, cytoplasm; OG, oil granules; SG, starch granules; SV, small vacuoles. Black arrowheads, small astaxanthin granules; white arrows, plastoglobules; black arrows, transparent hole in dissolving astaxanthin granule. Scale bars represent: $\mathrm{A}, \mathrm{E} \& \mathrm{~F}$, $1 \mu \mathrm{m} ; \mathrm{B}, \mathrm{C} \& \mathrm{D}, 0.5 \mu \mathrm{m}$.

\section{Changes of cell wall}

In green cells, there was little structure in the extracellular matrix layer (Fig. 2B). However, under induction conditions, a higher number of substances appeared in this layer in both non-thick-walled cells (Fig. 4A) and thick-walled cells (Fig. 4B). In thick-walled cells, the electron density and width of the secondary cell wall gradually increased as these substances accumulated in the extracellular matrix layer. Finally, the thickness of the secondary cell wall was approximately to $0.5 \mu \mathrm{m}$ with high electron densities, and the extracellular matrix layer disappeared (Fig. 4B-D) on the 10th day.

\section{Appearance and dissolution of astaxanthin granules}

During the late stage of vegetative growth, some small pigment granules, primarily containing $\beta$-carotene, ag- gregated in small vacuoles in the chloroplasts when nutrients were insufficient (Fig. 5A). However, under conditions of high light with acetate, the pigment granules appeared in the cytoplasm with higher electron densities and larger volumes (Fig. 5B-D). We believe that these increased pigment granules in the cytoplasm consisted of astaxanthin ester synthesized from $\beta$-carotene. We observed the formation process of large astaxanthin granules (Fig. 5D), which was shown in Fig. 5B \& C. In the cytoplasm, many new accumulated small astaxanthin ester granules came together to form a large astaxanthin granule. Meanwhile, there were a large number of oil granules that appeared and closed the astaxanthin granules. The oil granules were similar in size to astaxanthin granules, and some were even larger than astaxanthin granules. In thick-walled cells, no astaxanthin granules were concentrated around the nucleus, but the concentration of astaxanthin granules was observed in non-thick-walled cells (Fig. 3D). Moreover, the electron density of astaxan- 

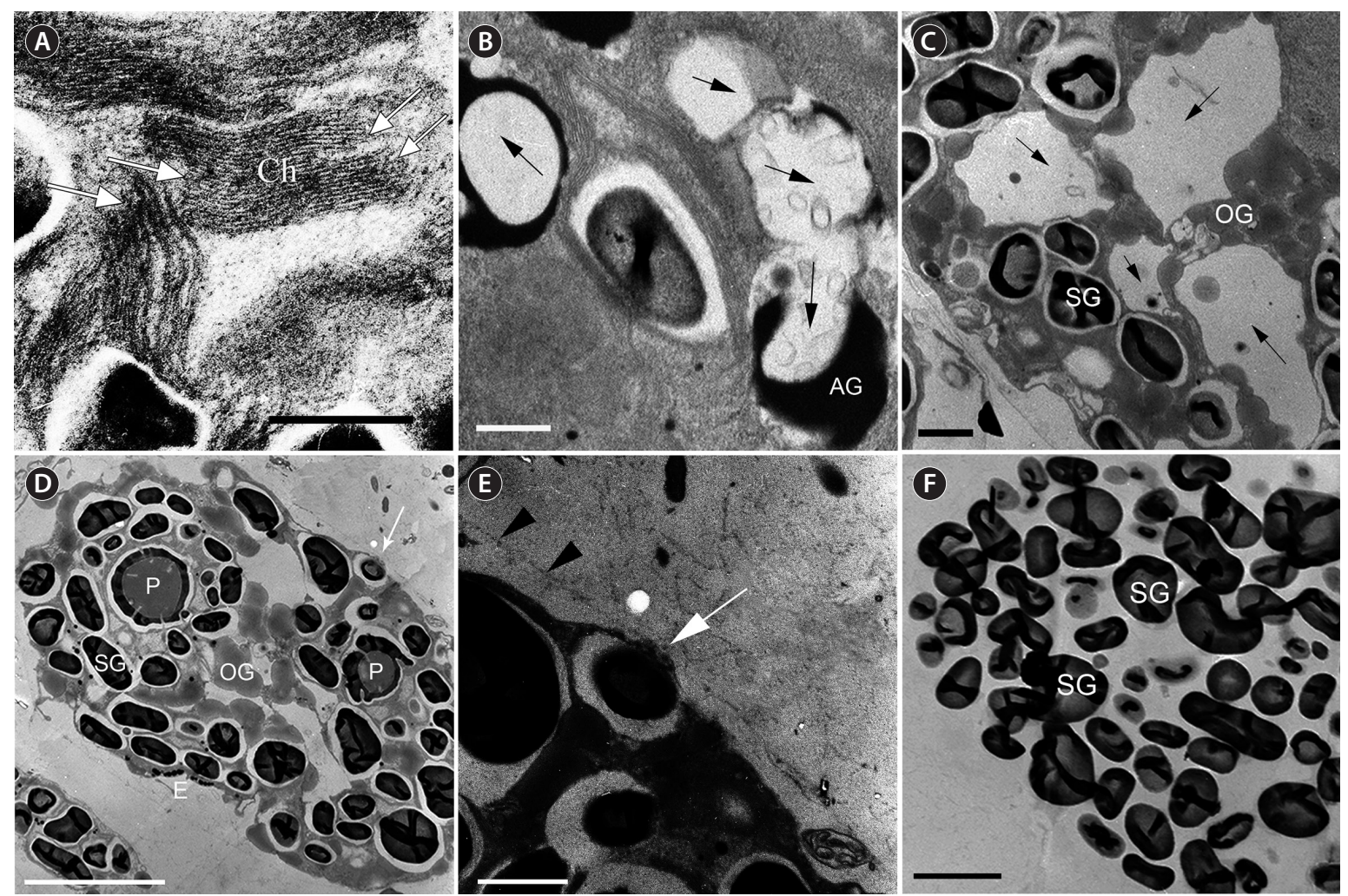

Fig. 6. Process of cell damage. (A) Detail diagram of chloroplast damage on the second day's cell under induced conditions. (B) Detail diagram of astaxanthin granules degradation in the sixth day's non-thick-walled cell under induced conditions. (C) Detail diagram of transparent area of damage cell. (D) Damaged cell on the verge of rupture. (E) Detail diagram of possible breaking point. (F) Residue of inclusions after cell rupture. AG, astaxanthin granules; Ch, chloroplast; E, eyespot; OG, oil granules; SG, starch granules; P, pyrenoid. White arrows, degraded chloroplast (A), possible breaking point ( $D \& E$ ); black arrows, transparent hole in dissolving astaxanthin granules $(B)$, transparent zone (C); black arrowheads, membrane of extracellular matrix (E). Scale bars represent: $A \& B, 0.5 \mu m ; C \& E, 1 \mu m ; D, 5 \mu m ; F, 2 \mu m$.

thin granules located at the edge of the cell was higher than that around the nucleus (Fig. 3D), suggesting that the astaxanthin granules located at the edge of the cell might be synthesized earlier.

During the middle stage under induced conditions (4-8 days), astaxanthin granules gradually dissolved, and this dissolution was present in both thick-walled cells (Fig. 5E) and non-thick-walled cells (Fig. 5F). Because of the existence of abundant oil structures in thick-walled cells, the transparent holes (black-tailed arrowhead in Fig. 5E \& F) that were exposed after the dissolution of astaxanthin granules covered by a mixture of astaxanthin and oil (Fig. 5E). During the later stage of induction (1018 days), most of the intracellular spaces were covered by the mixture so that the entire cell appeared red under an optical microscope (Figs 1E, F, 3B \& C). However, in nonthick-walled cells, the transparent holes were not fully covered because of an insufficient number of oil structures (Fig. 5F), which may have induced further damage.

\section{Observation of plastoglobules}

Plastoglobule-like structures could be seen in the chloroplast during the entire life of the cell, from the green vegetative growth cells to the red cyst cells (Figs 2 , $3 \& 5$ ). In green cells, the diameter of plastoglobules was approximately $50 \mathrm{~nm}$ (Fig. 2C). However, under high light with acetate, several abnormally enlarged plastoglobules could be observed; the diameters of some of these plastoglobules were as high as $160 \mathrm{~nm}$ (Fig. 5D). Under induced conditions, many plastoglobules were located near the newly formed starch granules, oil globules, and astaxanthin granules (Figs 3 \& 5). There appears to be a certain relationship between plastoglobules and the synthesis of starch, lipids, and pigments.

\section{Cell damages under induced condition}

Under induction with high light and acetate, different 
degrees of damages were noted in the algal cells. During the initial stage of induction, the sites of damage were primarily concentrated in chloroplasts, as indicated by the broken chloroplast (white arrowhead shown in Fig. 6A). With the dissolution of astaxanthin granules during the middle stage of induction, many transparent holes were exposed (Figs 5E, F \& 6B). As the extent of the damage increase, the volume of the transparent holes increased and led to cell breakage and eventually death (Fig. 6CF). We observed a damaged non-thick-walled cell on the verge of rupture (Fig. 6D). The white arrow in Fig. 6E indicated the possible breaking point where the cell wall and the membrane of the extracellular matrix almost disappeared. After the cell ruptured, a large number of starch granules and other inclusions were retained (Fig. 6F).

\section{DISCUSSION}

TEM revealed that the extracellular matrix of most of the cells gradually disappeared and was replaced by a thick secondary wall (i.e., thick-walled cells) with medium or high densities of electrons under induced conditions in H. pluvialis, similar to the findings of Damiani et al. (2006). Under stress, some cells retained the extracellular matrix without the formation of a secondary thick wall (i.e., non-thick-walled cells). Our observations revealed that there were different patterns in the dissolution of astaxanthin granules in the thick-walled and non-thick-walled cells. In thick-walled cells, astaxanthin was dissolved in the surrounding oil structures and occupied most of the intracellular space, which is consistent with the findings of Gwak et al. (2014) and Wayama et al. (2013). In contrast, the non-thick-walled cells had fewer oil substances and were more vulnerable to damage under conditions of high light with acetate compared with thick-walled cells, which was a pattern similar to the differences in the performance of "motile cells" and "non-motile cells" observed in Han's research (Han et al. 2012). Our study also revealed that there were different degrees of damage in cells under high light with high concentrations of acetate and that the initial type of damage consisted of the degradation of membranous structures, such the chloroplasts. According to previous research on H. pluvialis (Kobayashi et al. 1997, Focsan et al. 2017), these damages were likely caused by oxidative stress. In response to damages in $H$. pluvialis, astaxanthin granules and oil granules appeared and gradually increased in volume in the cytoplasm. In addition, astaxanthin existed in the form of granules during the early stage of induction and was distributed over a small area within cells in the middle and later stages, astaxanthin spread throughout the cells through the diffusion of oil substances, eventually covering the entire cell (Ota et al. 2018). Furthermore, this wide coverage made the entire cell appear deep red and possess a filtering effect under high light irradiation.

Overall, our results explain why severe damages always occurred in non-thick-walled cells and why most thick-walled cells could survive the completely induced stage. Two main reasons explain these patterns. First, the secondary thick cell wall had a higher electron density, which can reduce light intensity and provide protection to cells. Second, astaxanthin could not diffuse because of a lack of oil substances in non-thick-walled cells; thus, the protective ability of astaxanthin was weakened. Given these two facts, two future research directions should be explored to develop strategies to reduce cell damage during the induction stage. First, more work is needed to explore how to make green cells rapidly form secondary thick walls to protect the cells. Second, more work is needed to explore non-thick-walled cells accumulate large quantities of oil substances and provide carriers for the spread of astaxanthin to enhance the protective effect in H. pluvialis.

In addition, we observed that the plastoglobule-like structures both occurred in the green and the red cyst cells and that the morphological characteristics of these structures were similar to plastoglobules in Arabidopsis thaliana (Vidi et al. 2007). In higher plants, the number of plastoglobules increases in cells under aging or induction conditions (Bréhélin et al. 2007, Shanmugabalaji et al. 2013). We observed some abnormally enlarged plastoglobules with diameters as high as $160 \mathrm{~nm}$, compared with the 50-nm diameters of plastoglobules in green cells. In addition, many plastoglobules were located near the newly formed astaxanthin granules, oil granules, and starch granules. These observations revealed that the plastoglobules in H. pluvialis were similar in structure to higher plants and that the synthesis of astaxanthin, oil, and starch in $H$. pluvialis may be closely linked to these plastoglobules-like structures.

In conclusion, a series of structural changes during astaxanthin accumulation and cell damage in H. pluvialis under induction conditions had been observed. The results provide a morphological basis for future studies on H. pluvialis. 


\section{ACKNOWLEDGEMENTS}

This work was supported by the National Natural Science Foundation of China (Grant No. 31872555).

\section{REFERENCES}

Ambati, R., Phang, S. M., Ravi, S. \& Aswathanarayana, R. G. 2014. Astaxanthin: sources, extraction, stability, biological activities and its commercial applications-a review. Mar. Drugs 12:128-152.

Austin, J. R., Frost, E., Vidi, P. -A., Kessler, F. \& Staehelin, L. A. 2006. Plastoglobules are lipoprotein subcompartments of the chloroplast that are permanently coupled to thylakoid membranes and contain biosynthetic enzymes. Plant Cell 18:1693-1703.

Boussiba, S. 2000. Carotenogenesis in the green alga Haematococcus pluvialis: cellular physiology and stress response. Physiol. Plant. 108:111-117.

Bréhélin, C., Kessler, F. \& van Wijk, K. J. 2007. Plastoglobules: versatile lipoprotein particles in plastids. Trends Plant Sci. 12:260-266.

Chen, G., Wang, B., Han, D., Sommerfeld, M., Lu, Y., Chen, F. \& Hu, Q. 2015. Molecular mechanisms of the coordination between astaxanthin and fatty acid biosynthesis in Haematococcus pluvialis (Chlorophyceae). Plant J. 81:95-107.

Damiani, M. C., Leonardi, P. I., Pieroni, O. I. \& Cáceres, E. J. 2006. Ultrastructure of the cyst wall of Haematococcus pluvialis (Chlorophyceae): wall development and behaviour during cyst germination. Phycologia 45:616623.

Deruère, J., Römer, S., d'Harlingue, A., Backhaus, R. A., Kuntz, M. \& Camara, B. 1994. Fibril assembly and carotenoid overaccumulation in chromoplasts: a model for supramolecular lipoprotein structures. Plant Cell 6:119-133.

Evens, T. J., Niedz, R. P. \& Kirkpatrick, G. J. 2008. Temperature and irradiance impacts on the growth, pigmentation and photosystem II quantum yields of Haematococcus pluvialis (Chlorophyceae). J. Appl. Phycol. 20:411-422.

Fábregas, J., Domínguez, A., Maseda, A. \& Otero, A. 2003. Interactions between irradiance and nutrient availability during astaxanthin accumulation and degradation in Haematococcus pluvialis. Appl. Microbiol. Biotechnol. 61:545-551.

Fátima Santos, M. \& Mesquita, J. F. 1984. Ultrastructural study of Haematococcus lacustris (Girod.) Rostafinski (Volvocales). I. Some aspects of carotenogenesis. Cytologia 49:215-228.
Focsan, A. L., Polyakov, N. E. \& Kispert, L. D. 2017. Photo protection of Haematococcus pluvialis algae by astaxanthin: unique properties of astaxanthin deduced by EPR, optical and electrochemical studies. Antioxidants (Basel) 6:80.

Grünewald, K., Hirschberg, J. \& Hagen, C. 2001. Ketocarotenoid biosynthesis outside of plastids in the unicellular green alga Haematococcus pluvialis. J. Biol. Chem. 276:6023-6029.

Gwak, Y., Hwang, Y. -S., Wang, B., Kim, M., Jeong, J., Lee, C. -G., Hu, Q., Han, D. \& Jin, E. 2014. Comparative analyses of lipidomes and transcriptomes reveal a concerted action of multiple defensive systems against photooxidative stress in Haematococcus pluvialis. J. Exp. Bot. 65:4317-4334

Han, D., Wang, J., Sommerfeld, M. \& Hu, Q. 2012. Susceptibility and protective mechanisms of motile and nonmotile cells of Haematococcus pluvialis (Chlorophyceae) to photooxidative stress. J. Phycol. 48:693-705

Holtin, K., Kuehnle, M., Rehbein, J., Schuler, P., Nicholson, G. \& Albert, K. 2009. Determination of astaxanthin and astaxanthin esters in the microalgae Haematococcus pluvialis by LC-(APCI) MS and characterization of predominant carotenoid isomers by NMR spectroscopy. Anal. Bioanal. Chem. 395:1613-1622.

Imamoglu, E., Dalay, M. C. \& Sukan, F. V. 2009. Influences of different stress media and high light intensities on accumulation of astaxanthin in the green alga Haematococcus pluvialis. N. Biotechnol. 26:199-204.

Kobayashi, M., Kakizono, T. \& Nagai, S. 1993. Enhanced carotenoid biosynthesis by oxidative stress in acetateinduced cyst cells of a green unicellular alga, Haematococcus pluvialis. Appl. Environ. Microbiol. 59:867-873.

Kobayashi, M., Kakizono, T., Nishio, N., Nagai, S., Kurimura, Y. \& Tsuji, Y. 1997. Antioxidant role of astaxanthin in the green alga Haematococcus pluvialis. Appl. Microbiol. Biotechnol. 48:351-356.

Kobayashi, M. \& Sakamoto, Y. 1999. Singlet oxygen quenching ability of astaxanthin esters from the green alga Haematococcus pluvialis. Biotechnol. Lett. 21:265-269.

Lohscheider, J. N. \& Río Bártulos, C. 2016. Plastoglobules in algae: a comprehensive comparative study of the presence of major structural and functional components in complex plastids. Mar. Genomics 28:127-136.

Lorenz, R. T. \& Cysewski, G. R. 2000. Commercial potential for Haematococcus microalgae as a natural source of astaxanthin. Trends Biotechnol. 18:160-167.

Naguib, Y. M. 2000. Antioxidant activities of astaxanthin and related carotenoids. J. Agric. Food Chem. 48:1150-1154.

Ota, S., Morita, A., Ohnuki, S., Hirata, A., Sekida, S., Okuda, 
K., Ohya, Y. \& Kawano, S. 2018. Carotenoid dynamics and lipid droplet containing astaxanthin in response to light in the green alga Haematococcus pluvialis. Sci. Rep. 8:5617.

Rottet, S., Besagni, C. \& Kessler, F. 2015. The role of plastoglobules in thylakoid lipid remodeling during plant development. Biochim. Biophys. Acta 1847:889-899.

Shanmugabalaji, V., Besagni, C., Piller, L. E., Douet, V., Ruf, S., Bock, R. \& Kessler, F. 2013. Dual targeting of a mature plastoglobulin/fibrillin fusion protein to chloroplast plastoglobules and thylakoids in transplastomic tobacco plants. Plant Mol. Biol. 81:13-25.

Steinmüller, D. \& Tevini, M. 1985. Composition and function of plastoglobuli. Planta 163:201-207.

Tripathi, U., Sarada, R., Rao, S. R. \& Ravishankar, G. A. 1999. Production of astaxanthin in Haematococcus pluvialis cultured in various media. Bioresour. Technol. 68:197199.

Vidi, P. -A., Kessler, F. \& Bréhélin, C. 2007. Plastoglobules: a new address for targeting recombinant proteins in the chloroplast. BMC Biotechnol. 7:4.
Vishnevetsky, M., Ovadis, M. \& Vainstein, A. 1999. Carotenoid sequestration in plants: the role of carotenoidassociated proteins. Trends Plant Sci. 4:232-235.

Wang, B., Zarka, A., Trebst, A. \& Boussiba, S. 2010. Astaxanthin accumulation in Haematococcus pluvialis (Chlorophyceae) as an active photoprotective process under high irradiance. J. Phycol. 39:1116-1124.

Wayama, M., Ota, S., Matsuura, H., Nango, N., Hirata, A. \& Kawano, S. 2013. Three-dimensional ultrastructural study of oil and astaxanthin accumulation during encystment in the green alga Haematococcus pluvialis. PLoS ONE 8:e53618.

Ytterberg, A. J., Peltier, J. -B. \& van Wijk, K. J. 2006. Protein profiling of plastoglobules in chloroplasts and chromoplasts: a surprising site for differential accumulation of metabolic enzymes. Plant Physiol. 140:984-997.

Yuan, J. -P. \& Chen, F. 2000. Purification of trans-astaxanthin from a high-yielding astaxanthin ester-producing strain of the microalga Haematococcus pluvialis. Food Chem. 68:443-448. 